\title{
A Model of Differential Equations to Measure Mean Differences by Gender with Respect to Attitude towards Mathematics
}

\author{
Milka E. Escalera-Chávez \\ Universidad Autónoma de San Luis Potosi \\ Email: milkaech@uaslp.mx \\ Francisco Venegas-Martínez \\ Escuela Superior de Economía, Instituto Politécnico Nacional \\ Email: fvenegas1111@yahoo.com.mx \\ Arturo García-Santillán \\ UCC Business School, Universidad Cristóbal Colón \\ Email: arturogarciasantillan@yahoo.com.mx
}

Doi:10.5901/mjss.2016.v7n4p

Abstract

The learning-teaching process in mathematics has been modified, or at least influenced, by information technologies through one of its main instruments, the computer. The aim of this paper is to examine if there is a difference regarding gender on the Attitude towards Mathematics of the students of Accounting and Administration at UASLP. In order to test the hypothesis, we used a statistical method that contrasts differences of means; our study uses a sample of 120 students. The main empirical finding is that there is no difference between men and women regarding the attitude towards mathematics.

Keywords: Anxiety, Mathematics, Gender

\section{Introduction}

In 2015, the Ministry of Education in Mexico announced that "half of the students that finished high school remain in level 1 in mathematics: they just know how to multiply or add integer numbers, and $43.3 \%$ of them are unable to understand implicit information in a text ...". Also, in 2015, the Deputy Secretary of Higher Secondary Education indicated that "eight out of ten students that concluded high school have serious difficulties to solve complex arithmetic operations". He also indicated that it is important for the higher level schools be aware of this situation because it is probable that these students who have a low level of learning will be absent from classes and, eventually, will leave their studies.

It is clear that the process of teaching and learning mathematics has been modified by information technologies through the use of computers. Therefore, there is some concern with knowing if through this tool it is possible to overcome some deficiencies and thereby improve the learning process. Although there have been many studies about the positive impact of technology on the teaching-learning process of mathematics, it has been difficult to achieve systematic assessments of this impact (Galbraith and Hines, 1998, 2000). Some other authors as Fey (1989) have pointed out that regarding the use of technology in the learning-teaching process of mathematics "it is very difficult to determine the real impact in everyday Math classes." In this sense Kaput and Thompson (1994) pointed out that the acceptance of technological innovations that have been created and designed for other public (not necessarily for students) leads to difficult partnerships between the educational environment and the information technologies (Galbraith and Hines, 1998, 2000). These studies do not allow differentiation between attitudinal aspects, performance in mathematics, and technology aspects; however, in the seminal article of Galbraith and Haines (1998), they propose to make a distinction between attitudes related to technology for the learning of mathematics.

The proposed model formulated by Galbraith and Haines (1998) about the attitude towards mathematics is composed by a structure of five main factors. The main question of this study is stated as follows: Is there a difference regarding gender of students of Accounting and Administration at UASLP considering these factor? This research question leads to formulate the following hypothesis: is there a difference regarding gender between factors in attitudes 
towards mathematics and attitude toward computers?

Needless to say, mathematical knowledge is important. Therefore, it is necessary to understand and make a proper use of mathematics. In the United States, the National Council of Teachers of Mathematics (2004) pointed out the need for the use of Mathematics. In the teaching-learning process of mathematics, the information technologies (ICTs) have played an important role. Therefore, the study of teaching aids, as instruments that allows overcome some attitudinal deficiencies, are essential to provide feedback to the main actors in learning, the students.

This study is conducted among students in a public college in San Luis Potosi. We look for empirical evidence that allows us to identify whether the attitude towards mathematics can be enhanced by the use of information technologies implemented in the teaching-learning process, specifically the use of the computer. Also in this study, we look for reliable information regarding gender that allows us to have concrete arguments to generate proposals to both teachers and students. This proposal will intend to be guide for the better development of the teaching-learning process of mathematics.

\section{Attitude toward Mathematics and Gender Difference}

Although the mathematics is an important discipline in the training of the students, the students find Math as one of the toughest courses (Aliasgar, Riahini, Mojdehavar, 2010). Furthermore, these authors pointed out that the students are afraid of this discipline. This negative attitude leads to an anxiety state; in this sense, Stubblefield (2006), cited by Kargar, Tarmizi, Bayat (2010), emphasizes that anxiety toward mathematics is equivalent to having a very high level of concern, which probably stops or hinders the learning process. In this regard Richardson and Suinn (1972), cited by Sherman (2003), use the term "anxiety" as the worry toward Math. Moreover, this is one of the reasons why students avoid or not choose these courses (Garry 2005). Finally, anxiety toward mathematics is one of the causes in the low self-esteem and fear to failure.

Other studies have shown a significant relationship between mathematical reasoning, math anxiety and math attitudes. These studies have proven that students with a positive attitude towards learning mathematics are more motivated and engaged in their classes and learn more easily. Also, they are more motivated and committed to the classes than those students who have a negative attitude. Math anxiety appears in the same way in men and women (Hyde and Mertz, 2009). There is evidence that when a mathematics test is applied to the two groups, there are no significant differences in gender. Thus, we can think or inferred that their capability of acquiring mathematical knowledge is the same.

Other authors such as Jiménez (2004), cited by Espinoza (2010), show that during childhood the boys and girls consider mathematics as an important discipline for his life; however, he found that in adolescence there are noticeable and significant the differences, emphasizing that in men the achievement in mathematics is better.

Another important factor to be considered regarding this manifest difference towards mathematics between men and women could be influenced by the parents because they are the ones who, in many cases, transmit the idea to women about the belief that mathematics is a discipline for men. Therefore, women tend to choose areas of academic training where this discipline is not involved, that is, they avoid it in the majority of cases (Fennema and Sherman, 1978). Finally, Cevin and Dari (2010) pointed out in a study performed on gender that "gender is a factor that affects the learning of mathematics. They showed that male students have better perform on math than women."

\section{Theoretical Framework}

Galbraith and Hines, in 2000, proposed a theoretical model that allows us to make inferences about the factors involved in the attitude toward mathematics (see figure 1) 


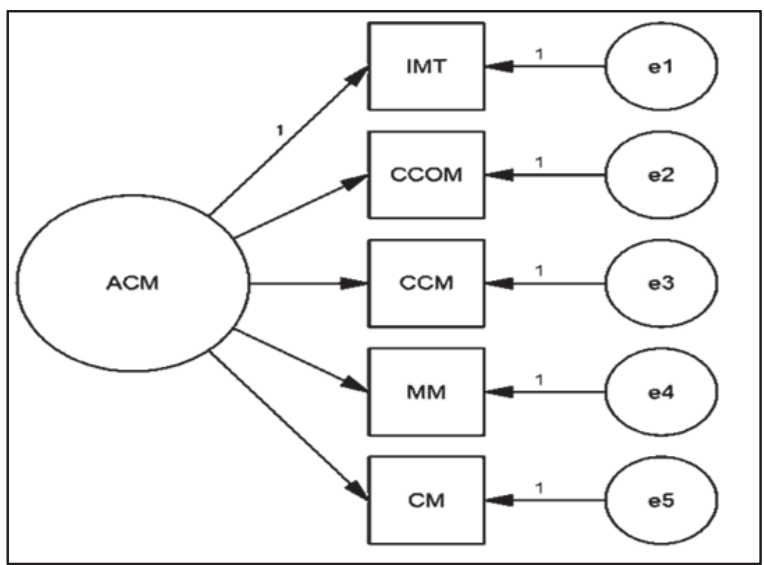

Figure 1. Theoretical model (Galbraith and Hines, 2000)

The model is composed by five dimensions: confidence toward mathematics, motivation toward mathematics, engagement toward mathematics, confidence toward computer and interaction between mathematics and computer. The variables and their dimensions are show in table 1.

\section{Methodology}

The study contrasts differences of means, and it tests whether the averages of the observable variable (attitude towards mathematics) of two groups (men and women) are statistically different one to the other. Also, it is a transverse scheme, considering that data collection is given only once during a given time. The selection criteria of the sample of size 120 were to include students who have enrolled at some program of Accounting and Administration at UASLP.

The selection criteria, also, were to include students that have completed at least one course of mathematics in the program that were studying and were available in the Institution at the time of applying the survey. A questionnaire that has provided by Galbraith and Haines (1998) was used, which consists of five sections: confidence towards mathematics (Items 1 to 8), motivation toward mathematics (items 9 to 16), engagement toward mathematics (24 items17), confidence toward computer (items25 32), and interaction between mathematics and computer (items 33 to 40). Each section consists of 8 items rated on a Likert scale. The scale range is from 1 (low) to 5 (very high). For the data processing program AMOS v 21 was used. The Table 1 describes each of the indicators, its concept and its encoding.

Table 1. Dimensions and its indicators

\begin{tabular}{lll}
\hline Confidence Toward & 1. & Mathematics is a subject in which I get value for effort \\
Mathematics & 2. & The prospect of having to learn new mathematics makes me nervous \\
3. & I can get good results in mathematics \\
4. I I am more worried about mathematics than any other subject \\
5. & Having to learn difficult topics in mathematics does not worry me \\
6. & No matter how much I study, mathematics is always difficult for me \\
7. & I am not naturally good at mathematics \\
8. & I have a lot of confidence when it comes to mathematics. \\
\hline Motivation Toward & 9. & Mathematics is a subject I enjoy doing \\
Mathematics & 10. Having to spend a lot time on a mathematics problem frustrates me \\
& 11. I don't understand how some people can get so enthusiastic about doing mathematics \\
12. I can become completely absorbed doing mathematics problems \\
13. If something about mathematics puzzles me, I would rather be given the answer than have to work it \\
\\
14. I like to stick at a mathematics problem until I get it out \\
15. The defy of understanding mathematics does not appeal to me \\
16. If something about mathematics puzzles me, I find myself find about it afterwards.
\end{tabular}




\begin{tabular}{|c|c|}
\hline \multirow{8}{*}{$\begin{array}{l}\text { Engagement Toward } \\
\text { Mathematics }\end{array}$} & 17. I prefer to work with symbols (algebra) than with pictures (diagrams and graphs) \\
\hline & 18. I prefer to work on my own than in a group \\
\hline & 19. I find working through examples less effective than memorizing given material \\
\hline & 20. I find it helpful to test understanding by attempting exercises and Problems \\
\hline & 21. When studying mathematics I try to link new ideas or knowledge I already have \\
\hline & 22. When learning new mathematical material I make notes to help me understand and remember \\
\hline & 23. I like to revise topics all at once rather than space out my study \\
\hline & 24. I do not usually make time to check my own working to find and correct errors \\
\hline \multirow{8}{*}{$\begin{array}{l}\text { Confidence Toward } \\
\text { Computer }\end{array}$} & 25. As a male/female (cross out which does not apply) I feel disadvantage in having to use computers \\
\hline & 26. I have a lot of self-confidence in using computers \\
\hline & 27. I feel more confident of my answers with a computer to help me \\
\hline & 28. If a computer program I am using goes wrong, I panic \\
\hline & 29. I feel nervous when I have to learn new procedures on a computer \\
\hline & 30. I am confident that I can master any computer procedure that is needed for my course \\
\hline & I do not trust myself to get the right answer using a computer \\
\hline & 32. If I make a mistake when using a computer I am usually able to work out what to do for myself \\
\hline Interaction Between & 33. I find it difficult to transfer understanding from a computer screen to my head \\
\hline \multirow[t]{6}{*}{ Computer-Mathematics } & 34. By looking after messy calculations, computers make it easier to learn essential ideas \\
\hline & 35. When I read a computer screen, I tend to gloss over the details of the mathematics \\
\hline & 36. I find it helpful to make notes in addition to copying material from the screen, or obtaining a printout \\
\hline & 37. I rarely review the material soon after a computer session is finished \\
\hline & 38. Following keyboard instructions takes my attention away from the mathematics \\
\hline & 39. Computers help me to link knowledge e.g. the shapes of graphs and their equations \\
\hline
\end{tabular}

Source: Galbraith and Haines (1998)

\section{Research Hypothesis}

The research hypothesis is given from the theoretical model about "Confidence in Math", which can be explained by five factors: confidence toward mathematics, motivation toward mathematics, engagement toward mathematics, confidence toward computer, and interaction between mathematics and computer. The graphical representation of the model is shown in Figure 2

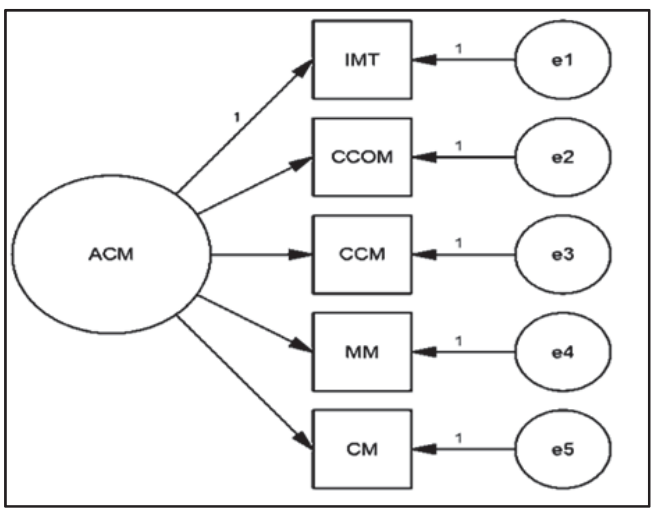

Figure 2. Galbraith and Haines model (2000)

Thus, the research hypothesis is proposed as follows:

$\mathrm{Hi}$ : There is a difference regarding gender among factors that influences attitudes towards mathematics and computers on the students of Accounting and Administration at UASLP.

In order to verify the truthfulness and accuracy of the hypothesis, we carried out a multi-group analysis of means and covariance structures (Sörbom. 1974). This kind of methodology allows joint estimation of the mean difference between latent variables, and the covariance structure exceeds the mean comparison methods commonly used, because 
this method corrects or adjusts the mean of the construct by the measurement error in the context of causal relationships (Escalera, Garcia, and Venegas-Martinez, 2013).

In order to perform the confirmatory factorial analysis of multiple groups (AGCM), the program AMOS v.22 was used. The analysis "AGCM" examines whether estimates of the model parameters were maintained unchanged in all groups (Kline, 2005). A prerequisite for measurement invariance among groups is to measure firstly the model without any restrictions. Subsequently are assigned to the model some restrictions as mentioned Byrne (2008).

In this regard, Steenkamp and Baumgartner (1998) indicate that there are different ways to measure invariance, among them are: the invariance in the model, the metric invariance, and invariance error. Therefore, the analysis starts with fitting the model without restriction, analyzing each group separately. The multi-group analysis of means and covariance structure allows us to obtain more reliable results and more appropriate when considering the measurement error of the latent construct.

In the model, the weight of regression is fixed to 1 and the mean of non-observable variables is 0 . It is not possible to estimate the mean values for both groups; however, Sörbom (1974) showed that when fixing the mean value of one group if we impose appropriate restrictions, relative to the regression weights and to the intercepts, then it is possible to obtain meaningful estimates of the mean factors for the two groups. In this paper was set at zero the factor of the mean group of women and the restrictions, were eliminated in the group of men.

\section{Discussion of Empirical Findings}

Table 2 shows the correlation of input data for the empirical analysis and it is seen that all variables are close to unity

Table 2. Matrix of correlations

\begin{tabular}{cccccc}
\hline Variables & CM & MM & CCM & CCOM & IMC \\
\hline CM & 1.000 & .208 & .114 & .282 & .085 \\
MM & & 1.000 & .392 & .337 & .171 \\
CCM & & & 1.000 & .265 & .323 \\
CCOM & & & & 1.000 & .446 \\
IMC & & & & & 1.000 \\
\hline
\end{tabular}

Source: Authors' own elaboration.

We found that the model has a good fit when using several groups $\left(X^{2}(3)=2.01 ; C F I=0.966 ;\right.$ RMSEA $=0.0$

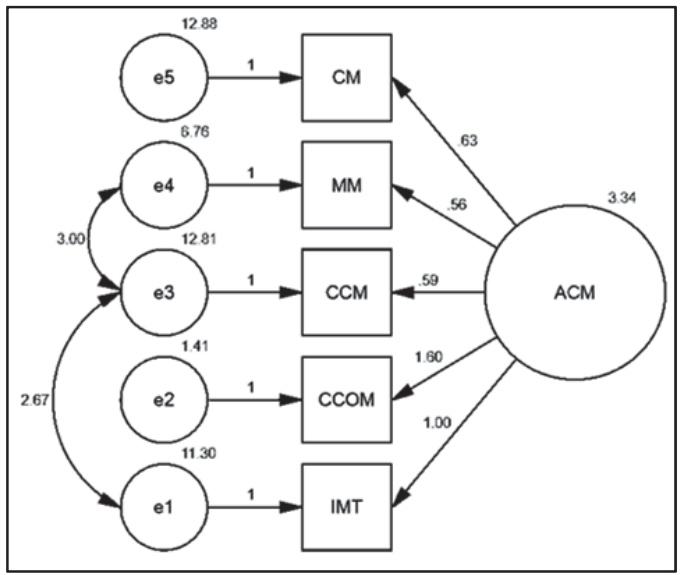

\begin{tabular}{|c|c|c|c|c|c|}
\hline$X^{2}$ & df & GFI & AGFI & CFI & RMSEA \\
\hline 2.001 & 3 & 0.993 & 0.966 & 0.994 & 0.00 \\
\hline
\end{tabular}


To demonstrate the invariance of the model, notice first the number of factors that best represents the data for both groups (male and female) was tested. Notice that there is not an equality constraints, it was selected as a criterion the goodness of fit of the model.
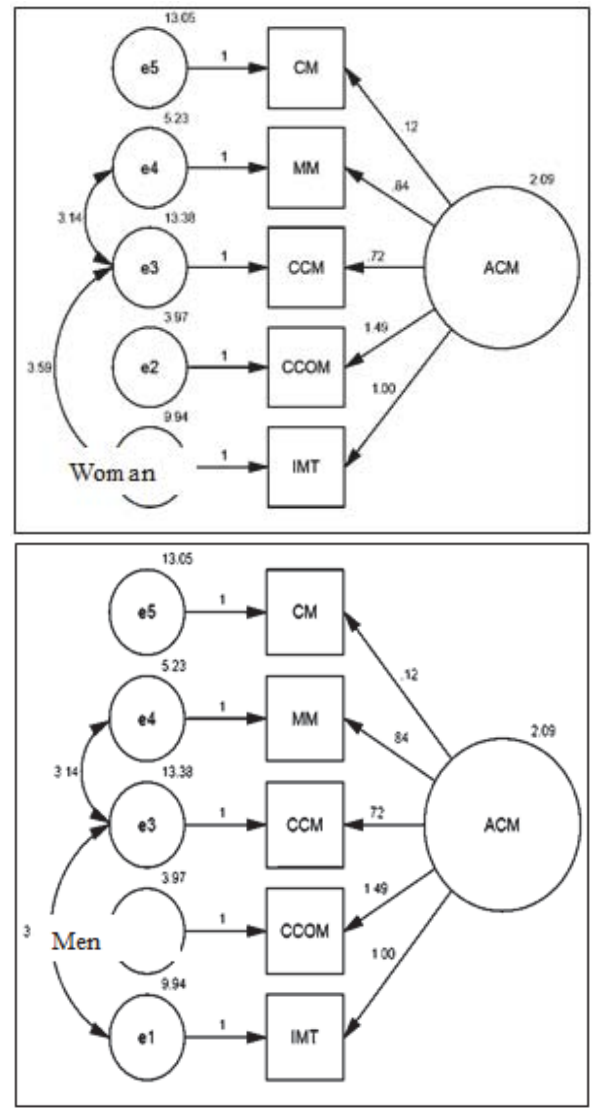

\begin{tabular}{|c|c|c|c|c|c|}
\hline$X^{2}$ & df & GFI & AGFI & CFI & RMSEA \\
\hline 8.5181 & 6 & 0.971 & 0.856 & 0.965 & 0.06 \\
\hline \multicolumn{6}{|c|}{ Graph and Index of the model }
\end{tabular}

The models are identified separately and the indexes indicate the goodness of the model fit for both groups. X2 (6) = 8.5181, $\mathrm{GFI}=0.971, \mathrm{AGFI}=0.856, \mathrm{CFI}==0.965$ and RMSEA $=0.06$. After confirming that the number of factors for both groups is the same, the mean of one of the groups was set at zero because it is not possible to estimate the mean for both groups (Sörbom (1974). In this study we chose by the group of men. The restrictions on the weights of regression and interception required the approach from Sörbom, These quantities will be generated automatically by AMOS software v.20.

The result of the test of goodness of fit provides evidence of a model with good fit (X2 (32) = 12,507; CFI = .952; RMSEA $=0.06$.). Table 3 shows the estimations of the mean of attitude towards mathematics corresponding to women group. Thereafter, to test invariance between equality constraints of groups, and between groups it was obtained the result of the goodness of fit test providing evidence of a model with good fit $(X 2(32)=12.507$; CFI = .952; RMSEA = 0.06). Table 3 shows the mean estimates of the attitude towards mathematics corresponding to the women group. 
Table 3. Mean differences (woman).

\begin{tabular}{|c|c|c|c|c|c|}
\hline & Estimate & S.E. & C.R. & P & Label \\
\hline ACM & 0.012 & 0.41 & 0.03 & 0.97 & mv_1 \\
\hline
\end{tabular}

Source: Authors' own elaboration

The critical value (CR 0030) is less than 1.96 which is not significant. That is, the mean group of men is not significantly different from the mean of the group of women. Let us remember that in the case of men, in this study the procedure set out by Sörbom (1974) was followed. Therefore, in this paper was set at zero the factor of the mean group of women, and the restrictions were eliminated in the group of men.

\section{Conclusions}

The results of this work allow us to test the following hypothesis: there is not a difference in relation to gender among the factors that influence attitudes towards mathematics and computers of students in Accounting and Administration of UASLP. In summary, the results show that there is no difference between men and women with regard to the attitude towards mathematics.

The results are consistent with those proposed by Hyde and Mertz (2009), which show that the anxiety occurs generally in the students of both genders. However, even when this study did not address the performance of students in mathematics, we can infer a deficiency on the results in relation to their performance.

The results obtained lead us to consider that education systems must think about the negative attitude that students have toward the discipline of mathematics, but especially should be focused on the design of strategies to improve student's attitude. Finally we emphasize the importance of the design of teaching strategies, because in current strategies, attitude is untreated, and is very likely that student, men and women, will continue showing a low level of performance in the field of mathematics.

\section{References}

Aliasgari M., Riahinia, N., and Mojdehavar, F. (2010). Computer-assisted instruction and student attitudes towards learning mathematics. Education, Business and Society: Contemporary Middle Eastern 3(1), 6-14.

Cervin, R. y Dari, N. (2009). Género, escuela y logro escolar en matemática y lengua de la educación media: Estudio exploratorio basado en un modelo multinivel bivariado. Revista Mexicana de Investigación Educativa, 14(43), 1051-1078.

Escalera, M., García., A. and Venegas-Martínez, F (2013). Attitude towards Statistics in College Students Differs among public and private universities? A. International Journal of Mathematical Archive-4(5), 229-234

Espinosa, C. (2010). Diferencia entre hombres y mujeres en educación matemática: ¿Qué pasa en México? Investigación y Ciencia. 46, 28-35.

Fennema, E. y Sherman, J. (1978) Sex-related differences in mathematics achievement and related factors: A further study, Journal for Research in Mathematics Education. 9, 189-203, 1978.

Fey, J. (1989). Technology and Mathematics Education: A survey of recent developments and important problems. Educational Studies in Mathematics 20, 237-272.

Galbraith. P. and Hines, C. (1998). Disentangling the nexus: attitudes to mathematics and technology in a computer learning environment. Educational Studies in Mathematics 36: 275-290, 1998.

Garry, V. S. (2005). The effect of Mathematics anxiety the course and career choice of high school vocational-technical education students. (Doctor of Philosophy). Drexel University.

Kaput, J. J. and Thompson, P. W. (1994). Technology in Mathematics Journal for Research in Mathematics Education 25(6), 676-684.

Kargara, M., Ahmad. R., and Bayatc, S. (2010). Relationship between Mathematical Thinking, Mathematics Anxiety and Mathematics Attitudes among University Students. Procedia Social and Behavioral Sciences 8, 537-542.

Hyde, J. and Mertz, J. (2009). Gender, culture, and mathematics performance. PNAS, 16(22), 8801-8807.

Sherman, B. and Wither, D. (2003). Mathematics Anxiety and Mathematics Achievement. Mathematics Education Research Journal, 15(2), 138-150.

Tuirán, R. (2015). Resultados de la prueba PLANEA. Recuperado el 4 de agosto de 2015 de http://planea.sep.gob.mx/content/general/docs/2015/PLANEA_MS2015_publicacion_resultados_040815.pdf 